
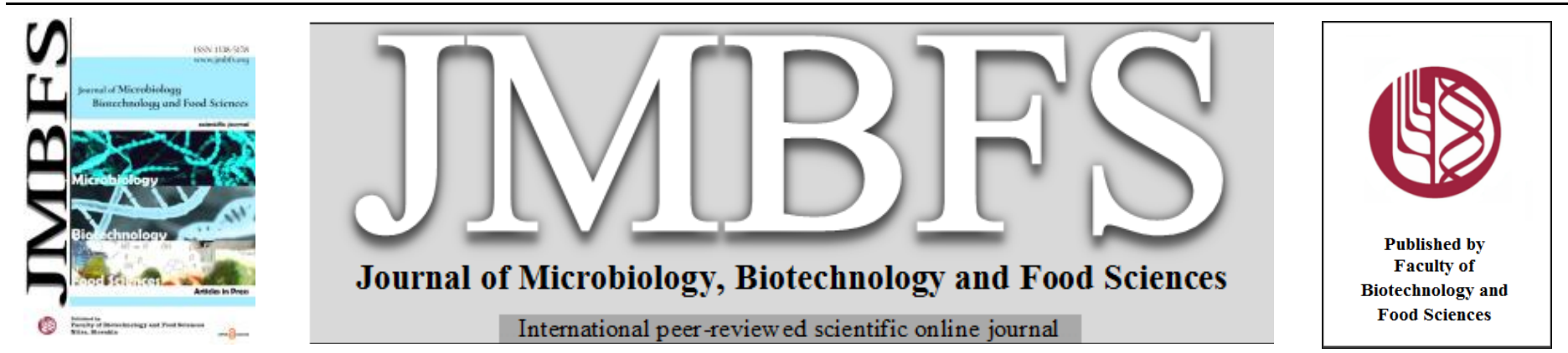

\title{
SUBTILISIN AN EMINENT MICROBIAL PRODUCT AS A POTENTIAL SKIN CARE REGULATOR OF MELANOGENESIS -A PARADIGM SYNCHRONIZED WITH IN VITRO / IN SILICO APPROACH
}

\author{
Anita Margret A. ${ }^{I *}$, Nivetha $I^{2}{ }^{2}$, Avila Jerley $A^{3}{ }^{3}$ and Aishwarya $S^{4}$ \\ Address(es): \\ ${ }^{1}$ Department of Biotechnology and Bioinformatics, Bishop Heber College, Tiruchirappalli-620017, Tamil Nadu, India. +91-9159626250. \\ ${ }^{2}$ Department of Biotechnology, National Centre of Excellence (MHRD), Thiagarajar College, Madurai - 625 009, Tamil Nadu, India. \\ ${ }^{3}$ Department of Zoology, Holy Cross College, Tiruchirappalli-625 002, Tamil Nadu, India. \\ ${ }^{4}$ Department of Bioinformatics, Stella Maris College, Chennai-600086, Tamil Nadu, India.
}

*Corresponding author: anitamargret@gmail.com

https://doi.org/10.55251/jmbfs.2847

\section{ARTICLE INFO}

Received 29. 3. 2020

Revised 17. 2. 2022

Accepted 21. 2. 2022

Published 1. 8. 2022

Regular article

OPEN $\partial_{\text {Access }}$

\begin{abstract}
Colour is considered as a foremost parameter for physical appearance and personal identification. The distinct coloration of skin, hair and eyes of humas are categorized based on the natural pigment melanin which is the final product of melanogenesis. Melanin establishes a primary protection to the skin by inducing photo protection. But the rapid mechanism of absorbing free radicals from the cytoplasm is defensive against UV light, thereby its enormous production and accretion leads to perturbing skin ailments. During the process of melanogenesis the core enzyme tyrosinase is employed and moderated by a main transcription factor called microphthalmia associated transcription factor (MITF), which is enhanced by both tyrosinase-related 1 and 2 proteins (TRP-1 /TRP-2). Amending this physiological process is considered to be the foremost mechanism in improving skin fairness. Conversely, there are numerous cosmetics commercially available to depigment skin colour, the alarm of adverse effects and reoccurrence of hyperpigmentation prevails as a hitch. Synthetic skin products cause remedy with adverse effects and hence there is a high demand for novel skin colouring agent. This work lays a pedal stone in promoting the appliance of a naturally derived protein subtilisin secluded from soil isolates of Bacillus sp. in cosmetic industry as skin whitening aspect. The extraction of subtilisin was detected by biochemical and HPLC assays coordinated with anti-melanogenesis activity by in vitro studies. Further, synchronization of molecular docking studies hoisted the protein as an effective ligand targeting TRP1 and TRP2 with energy minimization of $-675569 \mathrm{KJ} / \mathrm{Mol}$ and $-36957 \mathrm{KJ} / \mathrm{Mol}$.
\end{abstract}

Keywords: Melanogenesis, skin, Tyrosinase-related protein, Bacillus subtilis, Subtilisin, cosmetics, molecular docking

\section{INTRODUCTION}

Skin is a complex organ and known as the largest tissue of the body. It is fortuitous to be exposed with several vital and extraneous agents. The "epidermal melanin unit" facilitates the fortification of entire system by unblemished mechanism that is proceeded by the keratinocytes and melanocytes (Kanitakis, 2002; D'Mello et al., 2016). Melanin contributes for pigmentation in the physiology of an organism and is influenced by several external and biological parameters. Physical agent like UV light affects externally whereas inherited traits and hormones create an internal impact. Melanogenesis is a multi-phased natural process which utilizes tyrosinase as the foremost enzyme and administers microphthalmia-associated transcription factor thereby induces tyroinase-related protein (TRP1 and TRP2) as major targets of melanogenic enzymes. (Kim et al., 2013). Melanin is an active pigment that possesses multiple properties such as photoprotective, photosensitive and antioxidative. It participates in various physiological activities and primarily involves in protecting skin. The irregular functioning of melanin production indulges in indiscretion leading to hyperpigmentation of the skin. Though the pathological consequence is not much offensive yet it can cause significant cosmetic deformities which becomes a psychosocial burden for the patient. Apparently, this leads to diminutions in social functioning and low self-esteem (Chren et al., 2001).

Contemporary research associates melonogenesis disorders with progressive degeneration of nervous system that leads to several disparity in cognitive and motor neuron. Hence, the need for developing inhibitors to target multiple ailments has to be invigorated (Hara et al., 2000). Cosmetic industries target the regulation of melanogenesis as the principal requisite to improve fairness and skin texture. Fabrication of cosmetic products requires a precise mechanism that targets the production of melanin without offering side effects to the cells. Tyrosinase are considered as target to lessen the melanin production and thus increasing fairness in skin. Hence innovative skin colour lightening agents are on demand and several researches are initiated to generate them on large scale using various natural resources. Current scenario investigates varied phytochemical constituents and microbial proteins as sources. There are very few sightings that endorses tyrosinase as cosmetic targets to inhibit melanogenesis. Due to the undefined molecular mechanism and interaction of proteins in intracellular signalling pathways there is a necessitate to establish tyrosinase as direct inhibitors of melanogenesis in the cosmetics industry (Lin et al., 2012).

Soil derived bacterium like Bacillus subtilis establish themselves for producing extracellular protein subtilisin. It is a protease family derivative which facilitates a protective attribute in the microorganism by defending other evading pathogenic microorganisms. (Siezen et al.,1997; Nakjang et al., 2012; Duarte et al., 2016) Thereby enhance vital physiological functions such as cell growth, post translational processing of hormones (Rockwell et al.,2004), and defending the organism with the presence of digestive protease like subtilisin. (Withers-Martinez et al.,2004). They are mainly involved in hydrolysis of the peptide bonds (de Boer, 1991; Lowe, et al., 2015) enduring high commercial importance that initiates nucleophilic attack on peptide bond through a serine residue located at active site Subtilisin is a water-soluble proteolytic enzyme, whose application is widely used as a cleansing agent as cleansers at large scale industries and households. Alternatively, very few research supports the participation of subtilisin as protein hydrolysate production in both leather and cosmetics industry (Gupta et al., 2002). The pharmaceutical attribute of subtilisin holds a promise for its stability and therapeutic potency. It has the ability to digest and degrade gluten and can prevail amongst high acidic environment of stomach (Darwish $\boldsymbol{e t}$ al.,2019). The reports on toxicity studies exhibited a LD50 value was $1.8 \mathrm{~g} / \mathrm{kg}$. The substantiated clinical studies of subtilisin incited on animals revealed gastrointestinal disturbances which may be due to its proteolytic feature (Figueiredo et al., 2018). Hence, pharmaceutically engineered subtilisin with reduced protein degradation can develop ideal skin care potential. The application of this substantial protein in skincare diligence is at miniscule and hence there is a need of much research to hoist its potential as a cosmetic agent. This study has implemented subtilisin isolated from Bacillus subtilis as a lead candidate with the potential of regulating melanogenesis.

\section{MATERIAL AND METHODS}

\section{Soil sample collection and preparation}

The soil sample was collected from Anikurunthan, Ramanathapuram district, Tamilnadu, India. Approximately $5 \mathrm{gm}$ of soil was collected and transferred to lab 
under sterile conditions. Further, $1 \mathrm{gm}$ of constituent was supplemented to $5 \mathrm{~mL}$ of nutrient broth. This suspension was incubated at $35^{\circ} \mathrm{C}$ for 24 hours

\section{Isolation and characterization of Bacillus sp.}

Subsequently, the revived sample was serially diluted and plated on nutrient agar plates constituted with $20 \%$ raw milk, After a day's incubation the morphological (staining) and chemical attributes (biochemical test) of the isolate was identified based on Bergey's Manual of Systematic Bacteriology (Bergey and Holt, 2000)..A series of identification tests such as motility, starch hydrolysis, Gelatin hydrolysis, Casein hydrolysis, Citrate utilization, Voges-Proskauer VP, Methyl red (MR ), catalase, nitrate reduction, Triple sugar agar, Carbohydrate fermentation were performed.

\section{Production and assay of Subtilisin}

The soil isolate was fortified to produce subtilisin by exposing the culture to a standard media constituting the following composition: yeast extract $6.75(\mathrm{~g} / \mathrm{l})$, peptone $4.41(\mathrm{~g} / \mathrm{l})$, sodium chloride $6.08(\mathrm{~g} / \mathrm{l})$, casein $10.75(\mathrm{~g} / \mathrm{l})$ and glucose $5.00(\mathrm{~g} / \mathrm{l})$. At an optimum $\mathrm{pH} 7.5$ in room temperature the culture was standardised subtilisin production. . Though, subtilisin isolated from Bacillus sp. is considered to be extracellular, the intracellular constituents is also validated in this study. The conventional Anson method modified by (Yang and Huang, 1994; Mokashe and Patil 2016) assay using casein as substrate was followed in the study. The quantification of the product was validated using the following equation by calculating the tyrosine concentration using the regression equation obtained from its standard curve (Navaneeth et al., 2009; Boeckx et al.,2017). Tyrosine concentration $(\mu \mathrm{g} / \mathrm{ml})=\frac{\text { Test O.D }- \text { Control O.D }+0.285}{\mathrm{R}^{2}}$

The overall protein component present in the product was estimated using the standard Lowry's method (Lowry et al., 1951). The specific constituents of subtilisin was detected and validated with a HPLC run (Perkin Elmer Corp.Norwalk, U.SA) equipped with UV detector at standard absorption of 220 $\mathrm{nm}$. . The suspension was applied to C-18 column with an injection volume of 10 $\mathrm{ml}$ using $59 \%$ of Acetonitrile and $0.1 \%$ Trifluoroacetic acid as an eluent solvent.

\section{Tyrosinase Assay}

B16-F10 (ATCC ${ }^{\circledR}$ CRL-6475 ${ }^{\mathrm{TM}}$ ) cells were purchased from Hi media laboratories (Mumbai., India) and used for in vitro studies with standard cultural conditions. The analysis was performed by the protocol reported by (Baurin et al., 2002; Dong et al., 2020) with modifications by adapting the typical UV absorption studies at $475 \mathrm{~nm}$.

\section{In-silico Analysis - Molecular Docking}

Molecular docking was performed using GRAMMX web server. The target proteins and ligands were prepared before initiating docking.

\section{Peptide sequence retrieval and toxicity prediction}

The sequence of subtilisin from Bacillus sp with Id AOR97460.1, was retrieved from the NCBI protein database and checked for its toxicity using toxin-pred tool by breaking it into peptides.

\section{Target Protein sequence retrieval}

The sequences of target proteins namely TRP1 and TRP2 alternatively called Microphthalmia associated transcription factor were retrieved from Uniprot with the Ids Q60722 and 075030 respectively.

\section{Target protein structure prediction}

The 3D structure of TRP1 was downloaded from PDB since it was available in the ID 5M8P. There were no 3D structures available for TRP2 and Subtilisin and hence they were comparatively modeled using Swiss Model and Raptor X tools respectively.

\section{Structure validation}

The modelled structures of subtilisin and TRP2 were validated with Ramachandran plot using SAVS server.

\section{Protein - Protein Docking}

The target protein structures TRP1 and TRP2 were docked against the subtilisin using GRAMMX web server to check its interaction and binding. To browse the binding sites, protein and ligand (protein) was fixed in the docking software. The docking parameters were set as (200)/ (70) for Population size and Number of generations. Docking process started by analysing the interactions of the target and ligand. The results were viewed through docked poses to get interaction profile and interaction analysis in the table format.

\section{RESULTS AND DISCUSSION}

\section{Isolation of bacteria}

The bacteria were isolated from soil sample in a nutrient agar medium with $20 \%$ of raw milk and zone formation was observed around the colonies (Fig 1), thus indicates that the bacteria have the capacity of producing proteolytic enzymes and extracellular compounds. The identification of the isolates was preliminarily determined in accordance to Bergey's manual (Berkeley et al., 1984). Bacillus species are diverse with the presence of endospores which is considered as a foremost adaptation against heat. These species are selectively grown on media nourished with raw milk. Figure 1 illustrates the structural features of the isolate where the identifications were based on its colour. The Morphological characterization was based on classical macroscopic techniques of colour, form shape, and elevation of pure colonies and distinct growth patterns. Table 2 provides a clear morphological description of the isolate.

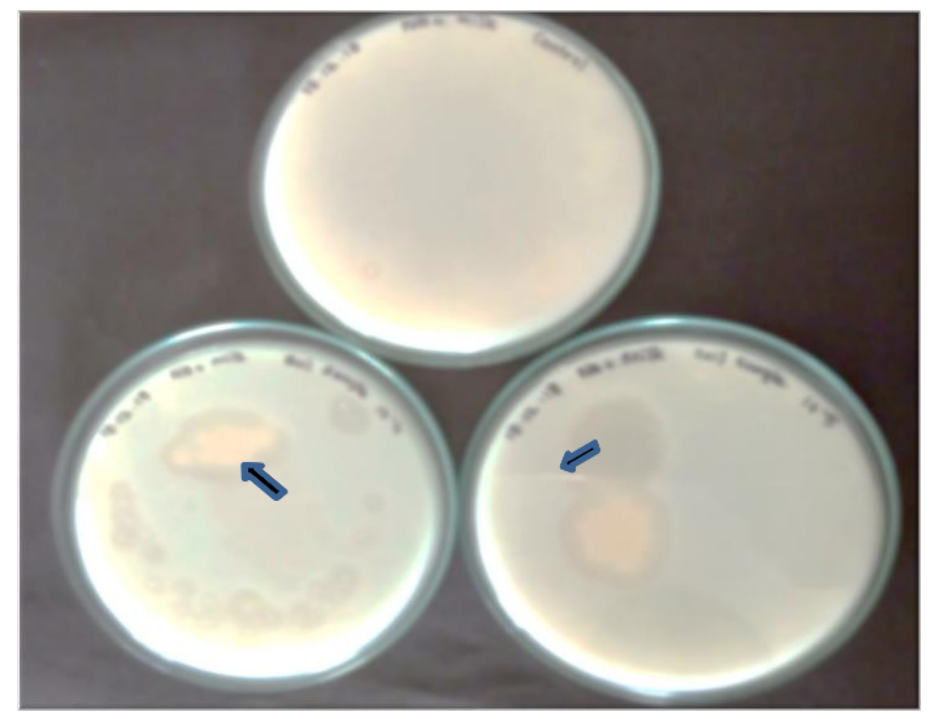

Figure 1 Colonies grown on Nutrient agar plates with $20 \%$ of milk (indicating zone formation)

Table 1 Morphological features of isolated bacteria

\section{Colony Morphology}

\begin{tabular}{lc} 
Colony Morphology & \\
\hline Framework & Circular \\
\hline Border & Curvy \\
\hline Elevation & Even \\
\hline Exterior & Smooth \\
\hline Consistency & Rough \\
\hline Color & Half-White (Cream tint) \\
\hline Opaqueness & Dense \\
\hline Staining (Gram's) & + \\
\hline Cell form & Rod \\
\hline
\end{tabular}

\section{Biochemical tests}

The primary biochemical tests were done to ensure that the bacteria are Bacillus $s p$. The table 2 shows the positive and negative results based on the biochemica activity of the isolated bacteria. The biochemical test results along with results from ABIS online software confirmed that the isolated bacterium was Bacillus $s p$ The series of tests depicted in table 2 augmented the capability of the organism to secrete both extracellular and intracellular enzyme. The structural organizational of the isolate was preliminarily recognized and were in concurrence to (Vargas $\boldsymbol{e}$ al., 2004). The present study was carried out to evaluate the production of subtilisin from a soil borne Bacillus species isolate. 
Table 2 Biochemical tests for isolated bacteria

\begin{tabular}{lc}
\hline Tests & Result \\
\hline Catalase & + \\
\hline Citrate & + \\
\hline Gelatin hydrolysis & + \\
\hline Gram staining & + \\
\hline Indole & + \\
\hline Methyl red & + \\
\hline Nitrate reduction & - \\
\hline Voges Proskauer & + \\
\hline Triple sugar agar & + \\
\hline Casein hydrolysis & + \\
\hline Starch & + \\
\hline Glucose & - \\
\hline Sucrose &
\end{tabular}

\section{Assay of subtilisin}

Existing as a protein digesting enzyme subtilisin has the capacity to undergo hydrolysis by utilizing a substrate and breaking peptide bonds Casein being the substrate is used by the protease activity there by increasing the free amino acid as end products. The polypeptide concentration is validated to assay the activity of the produced subtilisin. (Yang and Huang, 1994; Mokashe and Patil 2016). The amount of protein is related to the cleaved amino acid. In accordance to the habitat and physiology of microorganisms the quantity of protein varies. The quantitative assay performed exibited higher enzymatic activity $(520.82 \mathrm{U} / \mathrm{ml})$ on casein induced nutrient agar medium (Fig 2) which is in accordance to (Yanga $\boldsymbol{e t}$ al., 2000; Karadag et al., 2009).

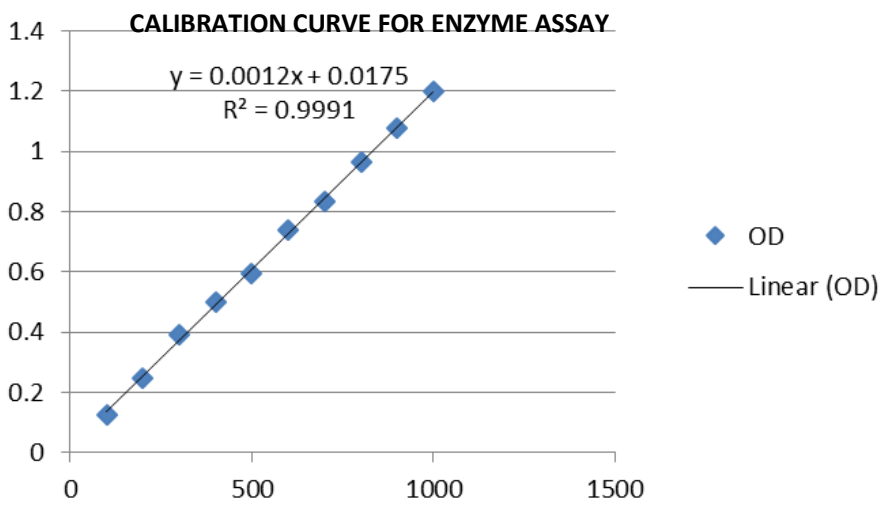

Figure 2 Standard graph of tyrosine with the concentration of $\mathrm{mg} / \mathrm{ml}$

\section{Protein estimation by Lowry's method}

The extraction process is followed by an estimation analysis and the extricated protein was estimated by Lowry's method (Fig 3). The concentration of crude protein was calculated from the standard graph of BSA. The optical density of the samples at various concentrations revealed the amount of protein in the extract. The crude protein was quantified with $1 \mathrm{mg} / \mathrm{ml}$ of standard whose value augmented for which the infinity was calculated with the regression coefficient. Subsequently in accordance to coefficient factor the quantity of protein was found to be 1.67 $\mathrm{mg} / \mathrm{ml}$. Fig. 3, There was a direct proportion between the intensity of the absorbance increase (y) and the amount of the protein (x) over the range 0-2.5 mg in a total volume.

\section{CALIBRATION CURVE FOR PROTEIN} QUANTIFICATION

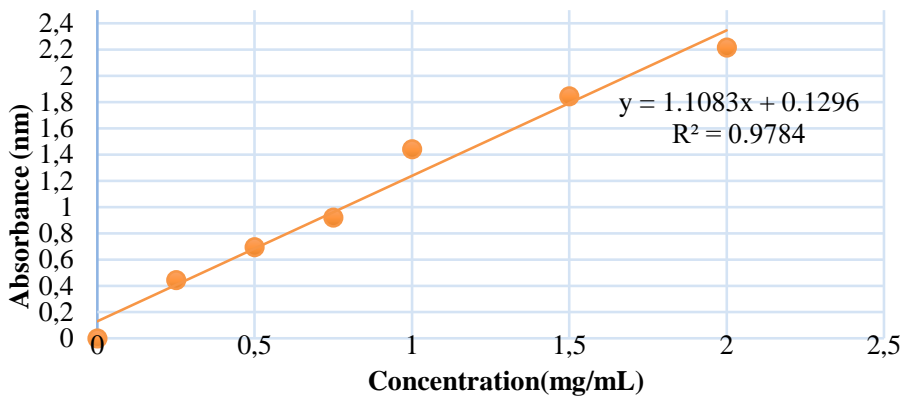

Figure 3 Standard graph of protein and the concentration of BSA was $\mathrm{mg} / \mathrm{ml}$

\section{HPLC Analysis}

High-performance liquid chromatography is favoured to identify and separate bioactive compounds and biomolecules (Ottesen and Svendsen, 1970; Danafar and Hamidi, 2015). The analytical instrument is profoundly used in separating various organic, phytocompounds and microbial proteins (Ikai, 1976; Strongin $\boldsymbol{e}$ al., 1978; Batrawi et al.,2017). This study evaluated the presence of subtilisin which is an alkaline serine protease. Intracellular (S1) and extracellular (S2) exudates of the bacterial isolates were taken as test samples. The HPLC chromatogram of intracellular exudate relatively has low number of peaks when compared to the extracellular sample. Active subtilisin hydrolyses the propeptide and can form strong subtilisin propeptide complex which could be demonstrated by HPLC analysis. According to the study of (Hu et al., 1996; Nakai et al., 2012) subtilisin was eluted at the retention time of $15.39 \mathrm{~min}$ which also formed a propeptide complex. In accordance with the above stated reference both the S1 (Fig 10) and S2 (Fig 11) exudates showed the peak with a retention time of 15.62 min and $15.0 \mathrm{~min}$. When analysing the peak $\mathrm{S} 1$ exhibited a greater area percentage $(5.36 \%)$ with an increased height of $2289 \mu \mathrm{V}$. Subtilisin E is an extracellular protein derived from Bacillus subtilis (Bryan, 1987; Bryan, 2000; Pannkuk et al.,2015) but the chromatogram of $\mathrm{S} 1$ also showed similar retention time as that of S2. This may be due to certain alterations in the bacterial physiology due to stress. Though various studies have been performed on bacterial isolates with HPLC, specific profiles on subtilisin are very few. This may be due to the need for vast injection volumes for resolving low- frequent peaks with the analytical instruments. For a bacterial isolate specific protein recovery is a real challenge because of its low optical density and Gram-positive species face this difficulty intensively. Furthermore, there is a need to profile on several microbial model organisms. This study requires a standardization with a comparative profile using subtilisin as a reference sample. There is a profound necessary of a systematic comparison among different strains of organisms in order explore their novel metabolites.

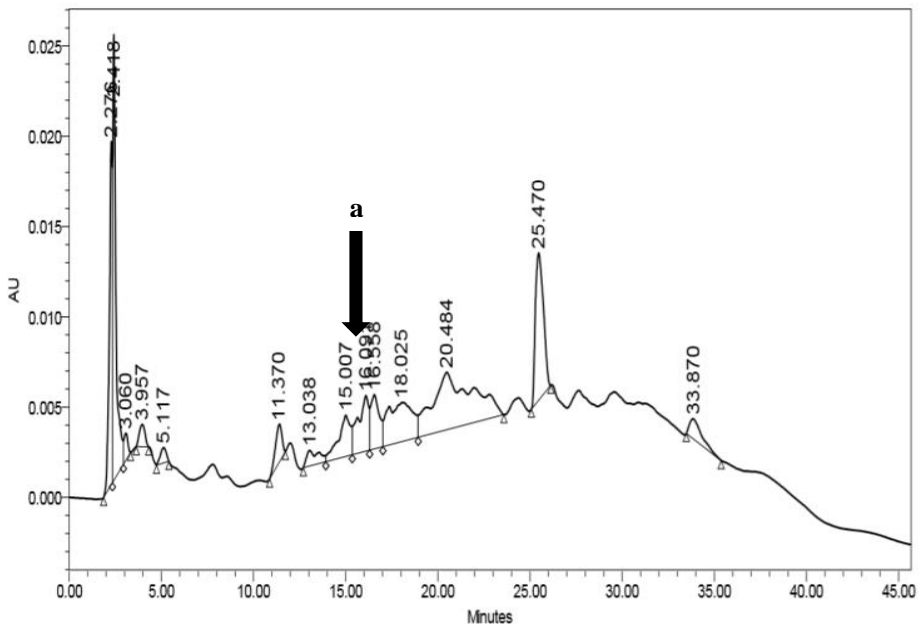

Figure 4 Chromatogram of Intracellular Crude Content showing Subtilisin propeptide (a ) complex from Bacillus sp.

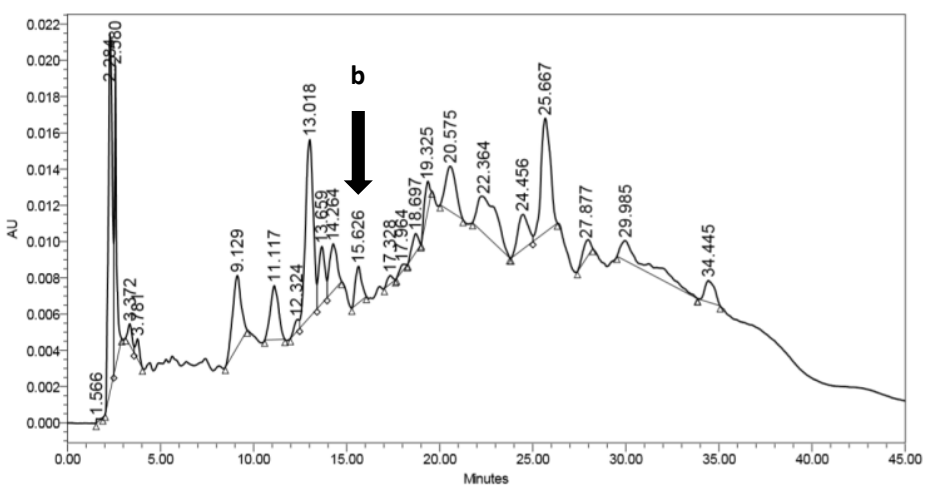

Figure 5 Chromatogram of Extracellular Crude Content showing Subtilisin propeptide (b) complex from Bacillus sp.

\section{Anti melanogenesis activity - Tyrosinase Inhibition Assay}

Subtilisin has received significant attention as detergent and is known as stain cutter (Kirk et al., 2002). However, little research has focused on its antimelanogenesis activity and this in vitro assay relates its potential in cosmetic field. Tyrosinase is a vital enzyme that promotes melanin biosynthesis. However, the accumulation of melanin causes serious skin ailments where, there is a need of 
anti-tyrosinase mechanism to exert skin protection and inhibit melanogenesis (Perluigi et al., 2002). B16-F10 cells constitutes of intracellular tyrosinase, and can monitor the antimelanogenesis through in vitro assays. The inhibition of the tyrosinase in oxidation of L-DOPA as its substrate was assessed. The results indicate subtilisin (crude) exhibited a maximum inhibitory $(1 \mathrm{mg} / \mathrm{mL})$ effect on tyrosinase activity. Although the inhibition percent is relatively low than positive control it exhibited a regulating potential when compared to negative control and can be incorporated as an innocuous compound devoid of adverse effects.

\section{TYROSINASE ASSAY}

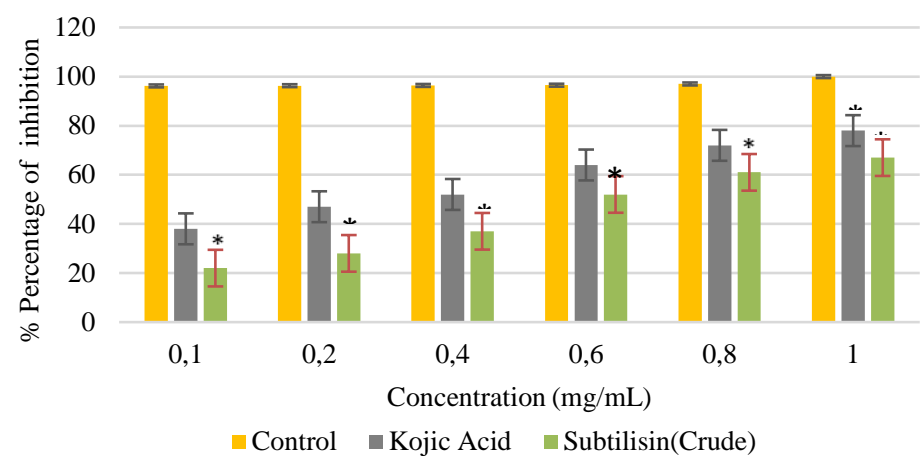

Acid (Positive Control) ; Subtilisin Crude (Test Sample) Data expressed are the means $\pm \mathrm{SEM} * \mathrm{P}<0.05$ of triplicate measures in comparison to the negative control (without the presence of inhibitor)

\section{In silico and Molecular docking studies}

\section{Toxicity Prediction of Subtilisin}

There is an excessive commercial application of subtilisin and hence there is a significant need to assay its hostile effect. Evaluating the toxicity of a distinct or assorted lead molecules with animal models is a tedious long-term process that involves high expenditure (Valerio, 2009). In silico tools can significantly support toxicity assessment and can limit the number of clinical trials. It comprises potential approaches to assay the rate of toxicity in a compound by scheming related computational algorithms and programmes which can relatively reduce the need of animal studies (Raies and Bajic 2016). The protein sequence of subtilisin that was retrieved from Uniprot was subjected to toxicity prediction using Toxinpred web server and the results are provided in table 3. The amino acid and peptide composition is assessed based on SVM model to discriminate toxic from non-toxic peptides. Where the resulted peptides were found to be non-toxic and there were no mutations found on the sequences. It showed good scores that ranged from -0.37 to -1.38 which is consistent with global binary models (Li et al.,2017) The molecular weights were was within $500 \mathrm{KD}$ which is an ideal mass for a drug

Figure 6 Tyrosinase Activity Assay in B16-F10 cell lines in the presence of Kojic

Table 3 Toxicity Prediction of Subtilisin

\begin{tabular}{|c|c|c|c|c|c|c|c|}
\hline Peptide sequence* & & $\begin{array}{l}\text { SVM } \\
\text { score }\end{array}$ & Hydrophobicity & $\begin{array}{l}\text { Hydropath } \\
\text { city }\end{array}$ & $\begin{array}{l}\text { Hydrophili } \\
\text { city }\end{array}$ & Charge & $\begin{array}{c}\text { Molecular } \\
\text { weight }\end{array}$ \\
\hline MRSKKLWISLLFALTLIFTMAFSNMSAQAA & No & -1.38 & 0.05 & 88 & -0.67 & 3 & 3392.59 \\
\hline GKSSTEKKYIVGFKQTMSAMSSAKKKDVIS & No Mutation & -0.37 & -0.24 & -0.62 & 0.44 & 5 & 3266.27 \\
\hline EKGGKVQKQFKYVNAAAATLDEKAVKELKK & No Mutation & -1.15 & -0.29 & -0.88 & 0.69 & 4 & 3321.33 \\
\hline DPSVAYVEEDHIAHEYAQSVPYGISQIKAP & No Mutation & -0.83 & $/-0.08$ & -0.43 & -0.02 & -3 & 3315.05 \\
\hline ALHSQGYTGSNVKVAVIDSGIDSSHPDLNV & No Mutation & -0.84 & -0.06 & -0.1 & -0.13 & -1 & 3081.8 \\
\hline RGGASFVPSETNPYQDGSSHGTHVAGTIAA & No Mutation & -1.01 & -0.09 & -0.46 & -0.11 & 0 & 2972.57 \\
\hline LNNSIGVLGVAPSASLYAVKVLDSTGSGQY & No Mutation & -1.63 & 0.04 & 0.45 & -0.45 & 0 & 2981.81 \\
\hline SWIINGIEWAISNNMDVINMSLGGPTGSTA & No Mutation & -1.09 & 0.06 & 0.24 & -0.52 & -2 & 3150.01 \\
\hline LKTVVDKAVSSGIVVAAAAGNEGSSGSTST & No Mutation & -0.99 & -0.01 & 0.38 & -0.03 & 0 & 2764.47 \\
\hline VGYPAKYPSTIAVGAVNSSNQRASFSSAGS & No Mutation & -0.6 & -0.07 & -0.11 & -0.25 & 2 & 2974.65 \\
\hline ELDVMAPGVSIQSTLPGGTYGAYNGTSMAT & No Mutation & -1.32 & 0.02 & 0.09 & -0.38 & -2 & 2989.77 \\
\hline PHVAGAAALILSKHPTWTNAQVRDRLESTA & No Mutation & -1.04 & -0.13 & -0.21 & -0.09 & 2 & 3212.07 \\
\hline TYLGSSFYYGKGLINVQAAAQ & No Mutation & -0.9 & 0.02 & 0.13 & -0.67 & 1 & 2251.84 \\
\hline MRSKKLWISLLFALTLIFTMAFSNMSAQAA & No & -1.38 & 0.05 & 88 & -0.67 & 3 & 3392.59 \\
\hline GKSSTEKKYIVGFKQTMSAMSSAKKKDVIS & No Mutation & -0.37 & -0.24 & -0.62 & 0.44 & 5 & 3266.27 \\
\hline EKGGKVQKQFKYVNAAAATLDEKAVKELKK & No Mutation & -1.15 & -0.29 & -0.88 & 0.69 & 4 & 3321.33 \\
\hline DPSVAYVEEDHIAHEYAQSVPYGISQIKAP & No Mutation & -0.83 & -0.08 & -0.43 & -0.02 & -3 & 3315.05 \\
\hline ALHSQGYTGSNVKVAVIDSGIDSSHPDLNV & No Mutation & -0.84 & -0.06 & -0.1 & -0.13 & -1 & 3081.8 \\
\hline RGGASFVPSETNPYQDGSSHGTHVAGTIAA & No Mutation & -1.01 & -0.09 & -0.46 & -0.11 & 0 & 2972.57 \\
\hline LNNSIGVLGVAPSASLYAVKVLDSTGSGQY & No Mutation & -1.63 & 0.04 & 0.45 & -0.45 & 0 & 2981.81 \\
\hline SWIINGIEWAISNNMDVINMSLGGPTGSTA & No Mutation & -1.09 & 0.06 & 0.24 & -0.52 & -2 & 3150.01 \\
\hline LKTVVDKAVSSGIVVAAAAGNEGSSGSTST & No Mutation & -0.99 & -0.01 & 0.38 & -0.03 & 0 & 2764.47 \\
\hline VGYPAKYPSTIAVGAVNSSNQRASFSSAGS & No Mutation & -0.6 & -0.07 & -0.11 & -0.25 & 2 & 2974.65 \\
\hline ELDVMAPGVSIQSTLPGGTYGAYNGTSMAT & No Mutation & -1.32 & 0.02 & 0.09 & -0.38 & -2 & 2989.77 \\
\hline PHVAGAAALILSKHPTWTNAQVRDRLESTA & No Mutation & -1.04 & -0.13 & -0.21 & -0.09 & 2 & 3212.07 \\
\hline TYLGSSFYYGKGLINVQAAAQ & No Mutation & -0.9 & 0.02 & 0.13 & -0.67 & 1 & 2251.84 \\
\hline ALHSQGYTGSNVKVAVIDSGIDSSHPDLNV & No Mutation & -0.84 & -0.06 & -0.1 & -0.13 & -1 & 3081.8 \\
\hline RGGASFVPSETNPYQDGSSHGTHVAGTIAA & No Mutation & -1.01 & -0.09 & -0.46 & -0.11 & 0 & 2972.57 \\
\hline LNNSIGVLGVAPSASLYAVKVLDSTGSGQY & No Mutation & -1.63 & 0.04 & 0.45 & -0.45 & 0 & 2981.81 \\
\hline SWIINGIEWAISNNMDVINMSLGGPTGSTA & No Mutation & -1.09 & 0.06 & 0.24 & -0.52 & -2 & 3150.01 \\
\hline LKTVVDKAVSSGIVVAAAAGNEGSSGSTST & No Mutation & -0.99 & -0.01 & 0.38 & -0.03 & 0 & 2764.47 \\
\hline VGYPAKYPSTIAVGAVNSSNQRASFSSAGS & No Mutation & -0.6 & -0.07 & -0.11 & -0.25 & 2 & 2974.65 \\
\hline ELDVMAPGVSIQSTLPGGTYGAYNGTSMAT & No Mutation & -1.32 & 0.02 & 0.09 & -0.38 & -2 & 2989.77 \\
\hline PHVAGAAALILSKHPTWTNAQVRDRLESTA & No Mutation & -1.04 & -0.13 & -0.21 & -0.09 & 2 & 3212.07 \\
\hline TYLGSSFYYGKGLINVQAAAQ & No Mutation & -0.9 & 0.02 & 0.13 & -0.67 & 1 & 2251.84 \\
\hline
\end{tabular}




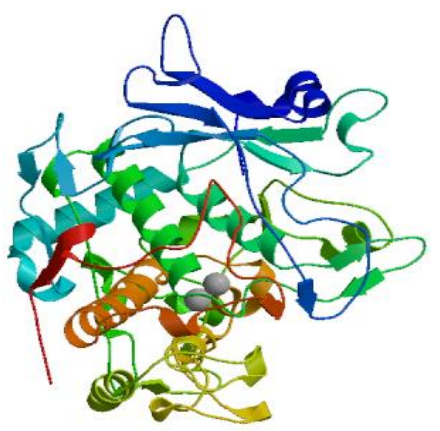

Figure 7 Homology modeled TRP2 Structure

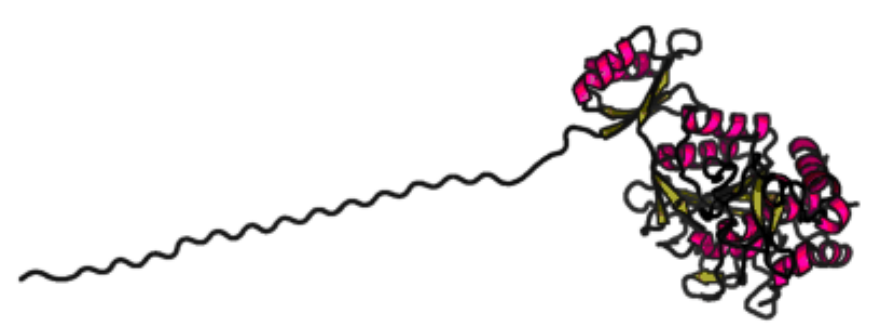

Figure 83 D Structure of Subtilisin

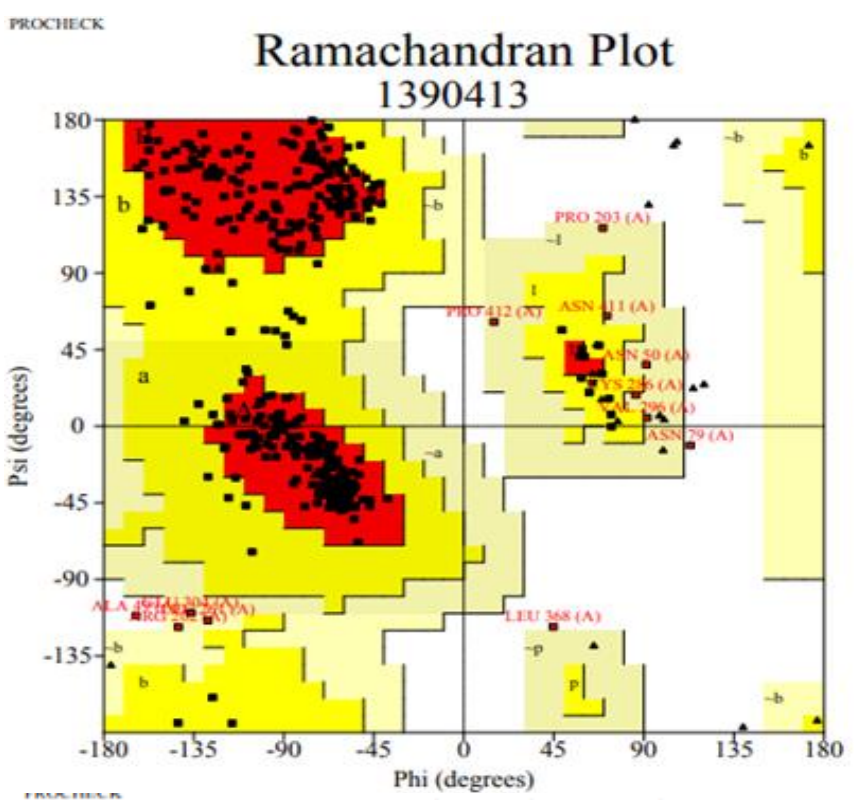

Ramachandran Plot 3183886

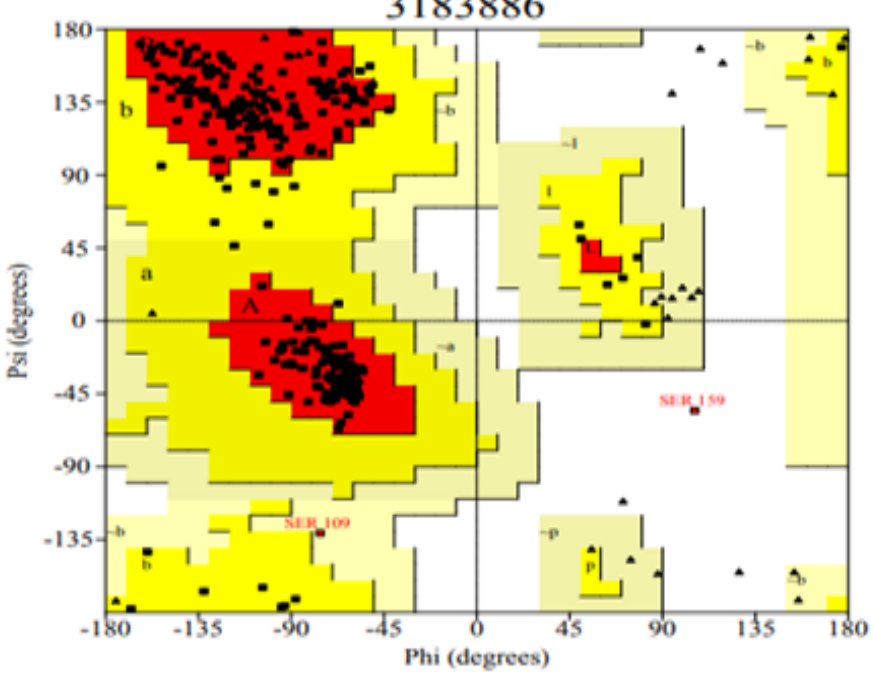

Figure 9 Ramachandran Plot for TRP 1 and 2
Protein structure can be characterized by the typical values of the main chain torsion angles $\phi$ and $\psi$ which can be visualized by a bidimensional diagram called Ramachandran plot. Sequence identity was found to be $54.85 \%$ with the structure of modelled TRP2. Ramachandran plot predicted the structure (TRP2) to be more feasible with the percentage of amino acids in the favourable region was found to be $87 \%$ (Figure 9). The result of Ramachandran plot analysis supported the highquality structure of the refined model.

\section{Protein - Protein Docking}

The molecular inhibitory interaction of subtilisin in the form of 3D structure (Fig $7 \& 8$ ) against melanogenesis inducing factors TRP1 and TRP2 was assayed in silco using molecular docking. Here, the protein subtilisin was considered as ligand and its interaction was found to be $-675569 \mathrm{KJ} / \mathrm{Mol}, 36957 \mathrm{KJ} / \mathrm{Mol}$ and after minimization TRP1 and TRP2 were docked with subtilisin through GRAMMX webserver. The ligands were found to be interacting well in the caveats with finest docked pose (Fig $10 \& 11$ ). Molecular structure of a protein in 3-dimensional form is a significant feature in docking. Unfortunately, only few crystal structures of enzymes are reported (Kim et al., 2004). Hence there was a need to model the second targeted protein of our study (TRP2). Adapting computational structural dynamics tools the unknown structure of a protein can be elucidated. (Xu, 2013) which can be further endorsed by Ramachandran plot.

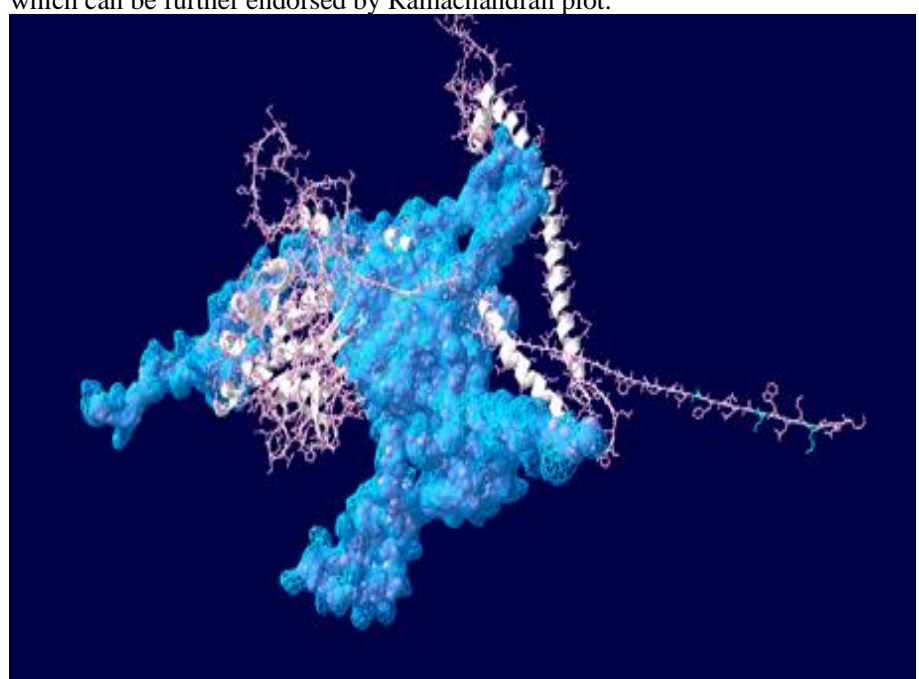

Figure 10 TRP1 docked with Subtilisin with the energy $-675569 \mathrm{KJ} / \mathrm{Mol}$ after minimization

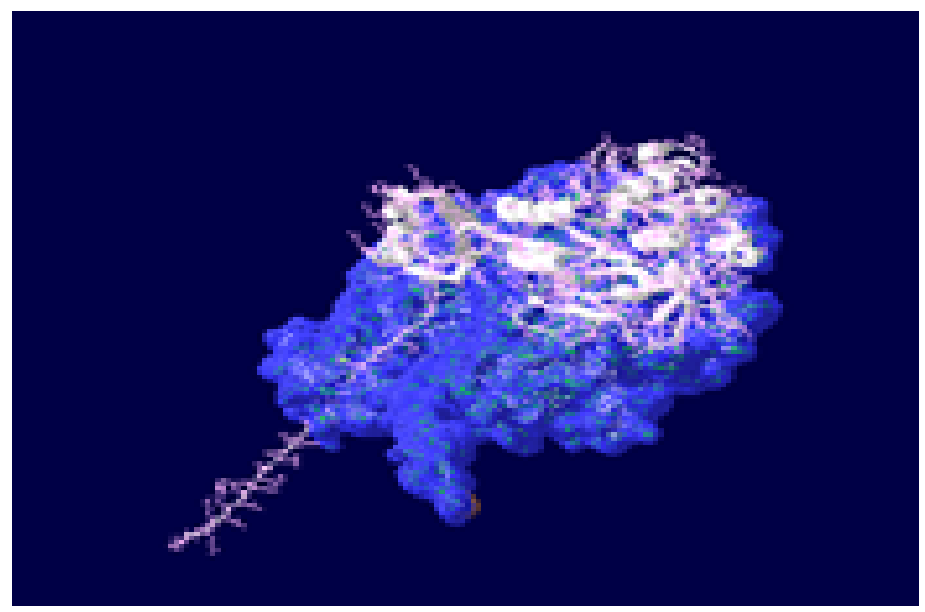

Figure 11 TRP2 docked with Subtilisin with the energy $-36957 \mathrm{KJ} / \mathrm{Mol}$

Protein interactions generally has the potential to form complexes with biomolecules (e.g. Ag-Ab, Enzyme-substrate complexes). The tertiary structure of proteins is necessary to understand the binding mode and affinity between interacting molecules. Protein interaction studies are deciphered through the tertiary features of proteins. Further using advance technology and computational simulation the 3-D structural (Santoyo et al., 2013). The software validating this docking event need to be more specific since the minimized energy confirmation is generally too large. This is due to the extensive size of proteins and when two of them interact massive amount energy is expelled. This study reveals one such assay where a high minimized energy is produced from both the targeted proteins. Hence this assay paves a baseline to elevate subtilisin as a lead compound in the field of drug discovery regulating melanogenesis. This can be substantiated by clinical trials which would elevate the standards of cosmetic industry. 


\section{CONCLUSION}

Melanogenesis is considered as a vital physiological event due to its potential of absorbing light and performing a photoprotective role. Though there are merits in its physiological process accretion of melanin could lead to skin aberrations and deformity. Regulation of this process is considered as a significant target in skin industry., Hence this study considers tyrosinase-related protein (TRP1 and TRP2) as target proteins. Subtilisin an alkaline serine protease is prospected as a ligand that has the capacity to regulate melanogenesis inducing factors. The Bacillus isolates from soil are considered to have a remarkable importance in the medicinal and food industry. But this work paves an initiation to validate its potency in cosmetic industry as a skin care agent. The isolated Bacillus sp. was morphologically and biochemically characterized. Further there was a stupendous production in subtilisin when the isolates where exposed to the production medium. The intracellular enzyme activity was found to be $520.82 \mathrm{U} / \mathrm{ml}$ with a very high protein content of $1.69 \mathrm{mg} / \mathrm{ml}$. RPC (Reverse Phase Chromatography) is a technique that analysis peptides and proteins efficiently with excellent resolution. The extracellular exudates extracted several peaks in the chromatogram when compared to intracellular sample. A specific peak with a retention time of 15.62 and $15.0 \mathrm{~min}$ was obtained relatively in both the samples to ensure the presence of subtilisin. The intracellular exudates revealed a higher area and height in the peak relatively to the extracellular sample. Further the analysis needs to be standardized with the reference protein. As an intimation of application a docking study was performed which provides the information that the enzyme can acts as a therapeutic agent for hyperpigmentation. The docking study (protein - protein interaction) was executed with the help of GRAMMX where the protein subtilisin was considered as a ligand. The prior ligand assay predicted subtilisin as a nontoxic protein. Further the docking score revealed a minimizing energy $(-675569 \mathrm{KJ} / \mathrm{Mo}$ \& $-36957 \mathrm{KJ} / \mathrm{Mol}$ ) against both targets (TRP1 \& TRP2) with a large quotient due to the high molecular weight protein interaction. Hence, this work lays a pedal stone in put forwarding the appliance of subtilisin in cosmetic industry as skin whitening aspect conclude that subtilisin can be a potential candidate against hyperpigmentation, since it is bearing a good regulating property with TRP2 Downstream processing, purification and standardization would bring in superior standard and claim its demand commercially. This study persuades the regulation of melanogenesis using subtilisin, a significant contribution in the field of cosmetics.

Acknowledgements: The authors concede the sustenance attained by Bishop Heber College, Tiruchirappalli, and Thiagarajar College, Madurai, Tamil Nadu, India. Facilities provided by the Department of Zoology, Holy Cross College, Tiruchirappall and Department of Bioinformatics, Stella Maris College Chennai, Tamil Nadu, India are gratefully accredited.

\section{REFERENCES}

Batrawi, N., Wahdan, S., \& Abualhasan, M. (2017). Analytical Method Validation of High-Performance Liquid Chromatography and Stability-Indicating Study of Medroxyprogesterone Acetate Intravaginal Sponges. Analytical chemistry insights, 12, 1177390117690152. https:// dx doi.org/10.1177/1177390117690152 Baurin, N., Arnoult, E., Scior, T., Do, Q.T. \& Bernard, P. (2002) .Preliminary screening of some tropical plants for anti-tyrosinase activity. Journal of Ethnopharmacology, 82(2-3), 155-158. https://dx.doi.org/10.1016/s0378 8741(02)00174-5

Bergey, D.H., Holt, J.G. (2000).Bergey's manual of determinative bacteriology, $9^{\text {th }}$ ed. Maryland, USA: Philadelphia: Lippincott Williams \& Wilkins Baltimore. https://dx.doi.org/10.1002/9781118960608.bm00009

Berkeley, R.C.W., Logan, N.A., Shute, L.A. \& Capey, A.G.(1984). Identification of Bacillus species. Methods in Microbiology, (Vol. 16): London:Academic Press Inc. Elsevier Ltd. https://dx.doi.org/10.1016/s0580-9517(08)70397-0

Boeckx, J., Hertog, M., Geeraerd, A. \& Nicolai, B. (2017). Kinetic modelling: an integrated approach to analyze enzyme activity assays. Plant Methods 13, 69 https:// dx.doi.org/10.1186/s13007-017-0218-y

Bryan, P. (1987). Protein Engineering. Biotechnology Advances, (Vol. 5): London:Academic Press Inc. Elsevier Ltd

Bryan, P. (2000). Protein engineering of subtilisin. Biochimica et Biophysica Acta (BBA), 1543(2), 203-222. https://dx.doi.org/10.1016/s0167-4838(00)00235-1

Chren, M.M., Lasek, R.J., Sahay, A.P. \& Sands, L.P. (2001). Measurement properties of Skindex-16: a brief quality-of-life measure for patients with skin diseases. Journal of Cutaneous Medicine and Surgery, 5(2), 105-110. https://dx.doi.org/10.1177/120347540100500202

Danafar, H., \& Hamidi, M. (2015). Simple and Sensitive High-Performance Liquid Chromatography (HPLC) Method with UV Detection for Mycophenolic Acid Assay in Human Plasma. Application to a Bioequivalence Study. Advanced pharmaceutical bulletin, 5(4), 563-568. https://dx.doi.org/10.15171/apb.2015.076 Darwish, G., Helmerhorst, E. J., Schuppan, D., Oppenheim, F. G., \& Wei, G. (2019). Pharmaceutically modified subtilisins withstand acidic conditions and effectively degrade gluten in vivo. Scientific reports, 9(1), 7505. https:// dx doi.org/10.1038/s41598-019-43837-9
De Boer, A. S. \& Diderichsen, B. (1991). On the safety of Bacillus subtilis and B. amyloliquefaciens: A review. Applied Microbiology and Biotechnology, 36(1), 14. https://dx.doi.org/10.1007/bf00164689

D'Mello, S. A., Finlay, G. J., Baguley, B. C., \& Askarian-Amiri, M. E. (2016) Signaling Pathways in Melanogenesis. International journal of molecular sciences, 17(7), 1144. https:// dx.doi.org/10.3390/ijms17071144

Dong, J.W., Li, X.J., Liu, P.H., Wu, Y.P., Yang, C., Li, Y.-F., \& Zhang, Y.-Q (2020). Improving the antioxidant and anti- tyrosinase activities of Stemonae Radix by solid-state fermentation with Mucor circinelloides T2-12. Preparative Biochemistry $\quad \& \quad$ Biotechnology, 50(7), 682-688. https://dx.doi.org/10.1080/10826068.2020.172869

Duarte, A. S., Correia, A., \& Esteves, A. C. (2016). Bacterial collagenases - A review. Crit. Rev. Microbiol. 42,

https://dx.doi.org/10.3109/1040841X.2014.904270

Figueiredo, J., Sousa Silva, M., \& Figueiredo, A. (2018). Subtilisin-like proteases in plant defence: the past, the present and beyond. Molecular plant pathology, 19(4), 1017-1028. https://dx.doi.org/10.1111/mpp.12567

Gupta, R., Beg, Q. \& Lorenz P. (2002). Bacterial alkaline proteases: molecular approaches and industrial applications. Applied Microbiology and Biotechnology, 59 (1), 15-32. https://dx.doi.org/10.1007/s00253-002-0975-y

Hara, M., Yaar, M., Byers, H.R., Goukassian, D., Gonsalves, J ,Gilchrest,B.A. \& Fine RE. (2000). Kinesin participates in melanosomal movement along melanocyte dendrites. Journal of Investigative Dermatology, 114(3),438-443 https://dx.doi.org/10.1046/j.1523-1747.2000.00894.x

Hu, Z., Haghjoo, K. \& Jordan, F. (1996). Further Evidence for the Structure of the Subtilisin Propeptide and for its Interactions with Mature Subtilisin. The Journal of Biological Chemistry, 271(7), 3375-3384. https://dx.doi.org/10.1074/jbc.271.7.3375

Ikai, A. (1976).Denaturation of subtilisin BPN' and its derivatives in aqueous guanidine hydrochloride solutions. Biochimica et Biophysica Acta (BBA) Enzymology, 445(1), 182-193. https://dx.doi.org/10.1016/0005-2744(76)90171-6 Kanitaki, J. (2002). Anatomy, histology and immunohistochemistry of normal human skin. European journal of dermatology, 12(4): 390-399. https://dx.doi.org/10.1684/ejd.2013.2060

Karadag, D., Makinen, A.E., Efimova, E. \& Puhakka, J.A. (2009). Thermophilic bio hydrogen production by an anaerobic heat treated-hot spring culture $\begin{array}{lll}\text { Bioresource } \quad \text { Technology, 100(23), } & 5790-5795\end{array}$ https://dx.doi.org/10.1016/j.biortech.2009.06.035

Kim, S.S., Kim, M.J., Choi, Y.H., Kim, B.K., Kim, K.S., Park, K.J., Park S.M.,Lee, N.H. \& Hyun, C.G. (2013). Down-regulation of tyrosinase, TRP-1, TRP-2 and MITF expressions by citrus press-cakes in murine B16 F10 melanoma. Asian Pacific Journal of Tropical Biomedicine, 3(8), 617-622. https:/dx./doi.org/10.1016/s2221-1691(13)60125-2

Kirk, O., Borchert, T.V, Fuglsang ,C.C. (2002) Industrial enzyme applications Current Opinion in Biotechnology, 13(4), 345-35. https://dx.doi.org/10.1016/s0958-1669(02)00328-2

Li F, Fan D, Wang H, Yang H, Li W, Tang Y \& Liu G. (2017).In silico prediction of pesticide aquatic toxicity with chemical category approaches. Toxicology Research, 6 (6), 831-842. https://dx.doi.org/10.1039/c7tx00144d

Lin, Y.S., Chuang, M.T., Chen, C.H., Chien, M.Y. \& Hou, W.C. (2012). Nicotinic acid hydroxamate downregulated the melanin synthesis and tyrosinase activity through activating the MEK/ERK and AKT/ GSK3 $\beta$ signaling pathways. Journal of Agricultural and Food Chemistry, 60(19), 4859- 4864 https:/dx.doi.org/10.1021/jf301109p

Lowe, R.G., McCorkelle, O., Bleackley, M., Collins, C., Faou, P., Mathivanan ,S. Anderson, M. (2015)Extracellular peptidases of the cereal pathogen Fusarium $\begin{array}{lllll}\text { graminearum. Frontiers in Plant } & \text { Science,6 }\end{array}$ https://dx.doi.org/10.3389/fpls.2015.00962.

Lowry, O.H., Rosebrough, N.J., Lewis Farr, A. \& Randall, R.J. (1951). Protein measurement with the Folin phenol reagent. Journal of Biological Chemistry, 193(1), 265-275. [PMC free article] [PubMed]

Mokashe, N. \& Patil, U. (2016). Quantitative protease assay by substrate-agarose plate method. Journal of Microbiology, Biotechnology and Food Sciences, 6, 791793. https://dx.doi.org/10.15414/jmbfs.2016.6.2.791-793.

Nakai, T., Ono, K., Kuroda, S., Tanizawa, K., \& Okajima, T. (2012). An unusual subtilisin-like serine protease is essential for biogenesis of quinohemoprotein amine dehydrogenase. The Journal of biological chemistry, 287(9), 6530-6538. https://dx.doi.org/10.1074/jbc.M111.324756

Nakjang, S., Ndeh, D. A., Wipat, A., Bolam, D. N., \& Hirt, R. P. (2012). A novel extracellular metallopeptidase domain shared by animal host-associated mutualistic and pathogenic microbes. PLoS One 7,e30287. https://dx.doi.org/10.1371/journal.pone.0030287

Navaneeth, S., Bhuvanesh, S., Bhaskar, V., Kumar, P.V., Kandaswamy, S. K. J. \& Achary, A. (2009). Optimization of medium for the production of subtilisin from Bacillus subtilis MTCC 441. African Journal of Biotechnology, 8 (22), 6327-6331. https://dx.doi.org/10.5897/ajb2009.000-9480

Ottesen, M. \& Svendsen, I. (1970). The subtilisins. In Pearlman, G.E. and Lorand

L. eds. Methods Enzymology, 19, 199-215. https://dx.doi.org/10.1016/00766879(70)19014-8 
Pannkuk, E.L., Risch, T.S., \& Savary BJ. (2015). Isolation and identification of an extracellular subtilisin-like serine protease secreted by the bat pathogen Pseudogymnoascus destructans. PLoS One. 10(3):e0120508. https://dx doi:10.1371/journal.pone.0120508

Perluigi, M., De Marco, F., Foppoli, Coccia, R., Blarzino, C., Luisa Marcante \& M., Cini, C. (2003). Tyrosinase protects human melanocytes from ROS-generating compounds. Biochemical and Biophysical Research Communications, 305 (2),250-256, https:// dx.doi.org/10.1016/s0006-291x(03)00751-4

Raies, A.B \& Bajic, V.B. (2016). In silico toxicology: Computational methods for the prediction of chemical toxicity. WIREs Computational Molecular Science, 8(3), 147-172. https:// dx.doi.org/10.1002/wcms.1352

Rockwell, N.C. \& Thorner, J.W. (2004). The kindest cuts of all: Crystal structures of Kex 2 and furin reveal secrets of precursor processing. Trends in Biochemical Science, 29 (2),80-87. https://dx.doi.org/10.1016/j.tibs.2003.12.006

Santoyo, A.H., Barajas, A.Y.T., Altuzar, V., Cid, H.V. \& Barrera, C.M.(2013)

Protein-Protein and Protein-Ligand Docking. In T. Ogawa (Eds.), Protein Engineering Technology and Application, Tohoku University: Japan. https://dx.doi.org/10.5772/56376

Siezen, R.J. \& Leunissen, J.A. (1997). Subtilases: The superfamily of subtilisinlike serine proteases. Protein Science, $6 \quad$ (3),501523. https://dx.doi.org/10.1002/pro.5560060301

Strongin, A. Y., Izotova, L. S., Abramov, Z. T., Gorodetsky, D. I., Ermakova, L. M., Baratova, L. A., Belyanova, L. P. \& Stepanov, V. M. (1978). Intracellular serine protease of /Bacillus subtilis: Sequence homology with extracellular subtilisins. Journal of Bacteriology, 133(3), 1401-1411. https://dx.doi.org/10.1128/jb.133.3.1401-1411.1978

Valerio, L.G. (2009). In silico toxicology for the pharmaceutical sciences. Toxicology and Applied Pharmacology, 241(3), 356-370. https:/dx.doi.org/10.1016/j.taap.2009.08.022

Vargas, V. A., Delgado, O. D., Kaul, R. H. \& Mattiasson, B. (2004). Lipaseproducing microorganisms from a Kenyan alkaline soda lake. Biotechnology Letters, 26, (3) 81-86. https://dx.doi.org/10.1023/b:bile.0000012898.50608.12

Withers-Martinez, C., Jean, L. \& Blackman, M.J. (2004) Subtilisin-like proteases of the malaria parasite. Molecular Microbiology, 53(1), 5563. https://dx.doi.org/10.1111/j.1365-2958.2004.04144.x

Xu, D. \& Yang, Z. (2013). Ab Initio structure prediction for Escherichia coli: towards genome-wide protein structure modeling and fold assignment. Scientific reports, 3(1), 1895. https://dx.doi.org/10.1038/srep01895

Yanga, J.K., Shihb, I.L., Tzengc, Y.M. \& Wanga, S.L. (2000). Production and purification of protease from a Bacillus subtilis that can deproteinize crustacean wastes. Enzyme and Microbial Technology, 26(5-6), 406-413. https://dx.doi.org/10.1016/s0141-0229(99)00164-7

Yang, S. S. \& Huang, C. I. (1994). Proteases production by Amylolytic fungi in solid state fermentation. Journal of the Chinese Agricultural Chemical Society, 32 589-6.Google Scholar 